\title{
SERVICIO AL REY Y DIPLOMACIA CASTELLANA: DON JUAN MANUEL DE VILLENA \\ $(+1462)$
}

\author{
CÉSAR Olivera SERRANO \\ Universidad Complutense de Madrid
}

\begin{abstract}
SUMARIO
1. Introducción.- 2. Linaje y relaciones de parentesco de Juan Manuel de Villena.- 3. Primeros años en la Corte de Juan II de Castilla.- 4. AI servicio de Enrique IV. Las embajadas a Francia (1455-1458).- 5. La complicada adquisición de un señorío: del condado de Cangas y Tineo al señorío de Belmonte de Campos.- 6 . Conclusión.
\end{abstract}

\section{INTRODUCCIÓN}

La diplomacia castellana en tiempos de Enrique IV (1454-1474) estuvo dirigida por un reducido núcleo de consejeros reales y desarrollada por un grupo de emabajadores que solían tener un estrecho grado de relación con ellos. Aunque contamos en la actualidad con algunos buenos estudios de naturaleza política que exponen el curso de los acontecimientos ${ }^{\mathrm{I}}$, no sucede lo mismo con los protagonistas más directos de la negociación. Algunos de ellos son bastante conocidos porque aparecen en las crónicas y otros textos políticos de la época, como Alfonso de Palencia o Diego de Valera, que

'Para un estado de la cuestión, César OlIVERA SERRANo, La alianza franco-castellana (1366-1463): una revisión historiográfica, "I Jornadas de Historia sobre Relaciones Internacionales", Madrid, 20 al 22 de octubre de 1994 (actas en preparación). 
reunieron la doble condición de cronistas y embajadores. Otros consejeros han sido estudiados en el seno de investigaciones globales de algunos reinados. Sin embargo la mayoría de ellos no ha sido objeto de una investigación detenida, aunque desde hace poco tiempo algunos estudios han empezado a mostrar su perfil social o profesional en el marco de una metodología prosopográfica. Desde este punto de vista han sido estudiados los embajadores que condujeron la negociación diplomática entre las monarquías castellana y portuguesa en el siglo $\mathrm{XV}^{2}$, así como los eclesiásticos que sirvieron a la monarquía Trastámara en las misiones diplomáticas ${ }^{3}$. Mucho queda aún por hacer en este campo del oficio diplomático en la Castilla del siglo XV como para ofrecer monografías parecidas a la que existen en el ámbito francés e inglés de aquella misma etapa ${ }^{4}$, pero de momento se pueden y se deben estudiar algunos ejemplos concretos como el que se ofrece en estas páginas.

En 1462 fallecía uno de los embajadores castellanos más característicos de la negociación con Francia bajo Enrique IV: don Juan Manuel de Villena. Los retazos que han quedado de su vida nos permiten saber cómo era a mediados del siglo XV la carrera política de un embajador castellano, así como algunos de los usos diplomáticos de la Corte castellana, o los peldaños que debía recorrer un noble de rancio linaje como él -aunque sin fortuna- para abrirse camino en la sociedad y en los cerrados grupos que ejercían el poder. También se descubren a través de su perfil biográfico algunos asuntos de la diplomacia regia que él se encargó de sacar adelante y que han permanecido hasta ahora en la penumbra.

Don Juan Manuel de Villena no tuvo una carrera excesivamente larga en la actividad diplomática, pero obtuvo en ella la mayor parte de sus

${ }^{2}$ Isabel BECEIRO PITA, La consolidación del personal diplomático entre Castilla y Portugal (1392-1455), "La Península Ibérica en la la Era de los Descubrimientos, 1391-1455" (III Jornadas Hispano-Portuguesas de Historia Medieval, Sevilla, 1991). Actas en prensa. Sobre las relaciones en la época del Infante don Enrique SUAREZ FERNÁNDEZ, Relaciones entre Portugal y Castill OLMEDO BERNAL, El dominio del Atlóntico en), Madrid, 1960, y más recientemente, Santiago ${ }^{3}$ Te Banul Nen ${ }^{3}$ Jose Manuel NIETo Sorla, Iglesia y génesis del Estado Moderno en Castilla (1369-1480),
Madrid, 1993, pp. 290-306.

${ }^{4}$ Los estudios más representativos en este sentido son los de Donald QUELLER, The Office
Ambassador in the of Ambassador in the Middle Ages, Princeton, 1967; J. GERGUSON, English Diplomacy, 14221461, Oxford, 1972; Isabelle LE BIS, Pratique de la Diplomatie. Un dossier d'ambassadeurs (1985-1986), pp. 97-157; y Pierre CHapLArs, Enolish 1982. éxitos personales. Visitó con cierta frecuencia la corte francesa entre 1455 y 1459. No se le encomendaron misiones en otras Cortes europeas, lo cual indica que en su tiempo ya se estaba empezando a producir una cierta especialización de las misiones diplomáticas a partir del destino que tenían los embajadores o del conocimiento pormenorizado de los asuntos que debían tratar. A lo largo de aquellos años de constantes desplazamientos alcanzó metas de relativa importancia: un señorío, sueldos de la Corte, prestigio social, e influencia política. Pero para llegar hasta ese punto tuvo antes que recorrer una larga trayectoria en campos diversos al servicio del rey y al amparo de algunos Grandes que controlaban el Consejo real, como Alvaro de Luna, Juan Pacheco y el arzobispo Alonso de Fonseca. Su vida es un ejemplo elocuente de lo que significaba la carrera política para un hidalgo que partía desde abajo en la escala nobiliaria.

\section{LINAJE Y RELACIONES DE PARENTESCO DE JuAn MANUel DE VILlena}

Si el servicio al rey fue el hilo conductor de su actividad profesional, su pertenencia a la nobleza condicionó muchos de los fines personales que pretendió alcanzar a través de la actividad diplomática. El apellido Manuel le abrió algunas puertas, pero al mismo tiempo condicionó mucho su capacidad de promoción, porque la riqueza que disfrutaba en sus primeros años no se correspondía con la dignidad de su apellido. En su comportamiento se descubre un empeño contínuo, casi obsesivo, por aprovechar todas las oportunidades que le surgían al hilo de la carrera política en la Corte y en las misiones diplomáticas para alcanzar un status personal y familiar digno de sus orígenes.

El linaje de los Manuel era uno de los más afamados de Castilla a mediados del siglo $\mathrm{XV}$, aunque había perdido en todas sus ramas la mayor parte del patrimonio, títulos e influencia que había llegado a tener en el siglo anterior. Salvador de Moxó incluye a los Manuel en el grupo linajes de la nobleja vieja que lograron sobrevivir a duras penas en la época Trastámara, ya que su importancia política, social y económica estaba muy mermadas ${ }^{5}$.

${ }^{5}$ Salvador de Moxó, De la nobleza vieja a la nobleza nueva. La transformación nobiliaria castellana en la Baja Edad Media, "Cuadernos de Historia", III (1969), pp. 190-195. 
De esta regla general quedaron al margen algunas mujeres de la familia Manuel que contrajeron matrimonio con algunos monarcas: Constanza Manuel, hija de don Juan Manuel, casada en primeras nupcias con Alfonso XI y en segundas con el infante don Pedro de Portugal; Juana Manuel, hija también de don Juan Manuel, casada con Enrique II de Trastámara, y finalmente Beatriz Manuel, hija de Constanza y don Pedro de Portugal, casada con Juan I de Castilla en 1383. Como todo el mundo sabe, los Trastámaras castellanos concedieron siempre gran importancia a estos enlaces, porque a través de ellos se reforzaba la legitimidad de la dinastía, puesta en tela de juicio en el reinado de Juan I de Castilla cuando el duque de Láncaster intentó alzarse con la corona castellana ${ }^{6}$. Durante el reinado de Juan II, algunos miembros del linaje Manuel fueron tratados como parientes del rey y se beneficiaron de algunas prerrogativas honoríficas, pero no consiguieron revitalizar la antigua riqueza y posición. Más áun, los mejores bienes del patrimonio Manuel pasaron a la corona, de modo que los enlaces reales se convirtieron en causa de descomposición y no en motivo de consolidación.

Varias ramas familiares descendían del célebre infante don Juan Manuel en el siglo XV. Algunos genealogistas posteriores, como Gonzalo Argote de Molina ${ }^{7}$ en 1575 y Luis Salazar y Castro $^{8}$ en 1688 , estudiaron con bastante detalle cada una de las principales y de otras colaterales hasta fines del siglo XVI, de modo que no merece la pena ahora extenderse demasiado sobre este aspecto. Es preferible dejar constancia de quienes eran los parientes y allegados más cercanos a don Juan Manuel de Villena cuando se inició en el servicio al rey para entender mejor los peldaños de su carrera.

Casi todos los Manueles que figuran a mediados del siglo XV en Castilla descendían de Enrique Manuel, hijo del infante don Juan Manuel, y de su segunda esposa, Blanca de La Cerda. Este don Enrique, llamàdo en ocasiones Enrique de Villena, residió en Portugal junto a su hermana Constanza Manuel donde ostentó el título condal de Sintra y Cascaes; recibió

${ }^{6}$ Luis SUÁREZ FERNÁndeZ, Historia del reinado de Juan I de Castilla, I, Madirid, 1977, p. 134-136.

${ }^{7}$ Gonzalo ARGOTE DE MOLINA, El conde Lucanor y Linaje de los Manueles, Sevilla, 1575. Biblioteca Nacional de Madrid, R. 2274.

${ }^{8}$ Luis SalazAR Y CASTRO, Advertencias históricas sobre las obras de algunos doctos escritores modemos, Madrid, 1688. En esta obra Salazar corrige algunos errores de algunos genealogistas anteriores. en Castilla el condado de Montealegre, y figuró entre los magnatès castellanos más influyentes en los reinados de Juan I, Enrique III y primeros años de Juan $\mathrm{II}^{9}$. Formó parte del Consejo de regencia en Castilla cuando Fernando de Antequera acudió a recibir la corona aragonesa tras el Fernando de Antequera acudió a recibir la corona ara De sus cuatro hijos, Pedro, Fernando, Leonor e Inés, nos interesa destacar especialmente a los dos primeros, porque de ellos descendían los Manueles más conocidos en la Corte de Juan II y Enrique IV.

El primero, Pedro Manuel, heredó de su padre el título sobre Montealegre y Meneses ${ }^{11}$, aunque no como conde, sino como simple señor, y fue el representante de la familia con más prestigio durante el reinado de Juan II de Castilla. Aparece citado de vez en cuando en las crónicas de la época. Era miembro del Consejo real y participó en algunas campañas contra Granada (como la de 1431); tomó parte junto al monarca en algunos episodios políticos relevantes, como las negociaciones de Tordesillas de $1434^{12}$. Fue partidario de don Alvaro de Luna, de quien llegó a cobrar acostamiento $^{13}$. Por su parentesco con el soberano se empleaba frecuentemente la expresión tio del Rey para designarle, aunque fuese en realidad un pariente algo lejano. En 1465 figuraba don Pedro Manuel como uno de los leales de Enrique IV frente a su hermano, el infante don Alfonso ${ }^{14}$. Las relaciones personales que mantuvo don Pedro Manuel con el personaje objeto

${ }^{9}$ Era miembro del Consejo Real; Juan de Mata CARRIAzo (ed), Crónica de Juan II de Castilla, por Alvar García de Santa María, Madrid, 1982, p. 7. Gonzalo Argote afirma que Ilegó a ser ayo de Juan II de Castilla.

${ }^{10}$ Codicilo otorgado el 6 de junio de 1414 en Illescas. Ultimas voluntades, en el lecho de muerte, declaradas el 8 de noviembre de 1414 en el monasterio de Santiago de Guadalajara. Se habla de él como mayordomo mayor de la reina de Aragon:
lo sucesivo AGS), Mercedes y Privilegios, leg. 10, fol. 132 .

"11Juan II le confirmó la merced sobre el señorío de Montealegre el 13 de septiembre de 1419. Real Academia de la Historia (en lo sucesivo RAH), Colección Salazar (en lo sucesivo Salazar), M-9, fol. 333-333v.

${ }^{12}$ Don Pedro Manuel asistió al rey en las reuniones que se organizaron bajo el seguro del conde de Haro con los nobles fieles y opuestos a don Alvaro de Luna; vid. Nancy F. MARINo 1992 , pp. 87, 92, 115 y 124 .

${ }^{13}$ En 1437 Pedro Manuel recibía del Condestable 30.000 maravedíes anuales; Salazar, A-5, fol. $42-43$.

${ }^{14}$ Don Alfonso, el rey de Avila, ordenó la confiscación del juro de 20.000 maravedís que cobraba de los recaudadores de las alcabalas de Valladolid y su Infantado; carta de don Alfonso (XI) dada en Avila el 15 de diciembre de 1465. AGS, Mercedes y Privilegios, leg. 10, fol. 134. 
de estas páginas, del que era tío carnal, no fueron demasiado cordiales, como tendremos ocasión de ver.

El segundo hijo de don Enrique Manuel, Fernando Manuel de Villena, después de haber vivido alguños años en Portugal con su tía la reina Constanza, se instaló en Castilla donde vivió una existencia tranquila, alejada de los vaivenes de la política general y loca ${ }^{15}$. De él han quedado pocas referencias documentales ${ }^{16}$. Fernando Manuel de Villena, o simplemente Fernando de Villena, como se le conocía en Portugal, no recibió de su padre ningún título ni tampoco transmitió nada a su hijo, don Juan Manuel de Villena. Contrajo matrimonio con Mencía de Fonseca, natural de Toro. De este matrimonio nacieron nueve hijos; don Juan Manuel de Villena, nuestro diplomático, era el segundogénito, y nació en una fecha que podría estar en torno a los años $1415-1420^{17}$. Las únicas propiedades importantes de esta familia pertenecían a doña Mencía de Fonseca y estaban diseminadas entre Toro y Olmedo, de modo que el patrimonio del futuro embajador procedía casi exclusivamente de su familia materna.

La escasez de patrimonio de ambas ramas familiares de los Manuel da sentido a un largo enfrentamiento judicial que se entabló entre ambas por el disfrute de un juro anual de 45.000 maravedís que el padre de ambos, don Enrique Manuel, había recibido de la corona y que acabó parando finalmente en la familia de don Juan Manuel ${ }^{18}$

El apellido Manuel sólo aportó prestigio al futuro embajador, pero poco más. La riqueza patrimonial de sus padres procedía de su madre,

${ }^{15}$ En 1444 ya había fallecido. Fue sepultado en la capilla de los Manuel en el convento de San Pablo (hoy día San Juan y San Pablo) de Peñafiel, según se desprende đel testamento de su hijo que más adelante comentaremos.

${ }^{16}$ Don Fernando Manuel recibió en 1429, tras la derrota de los Infantes de Aragón, 8.000 maravedíes de ayuda de costa y otros 8.000 de merced, al igual que su hijo don Juan Manuel Miguel Angel LADERO QueSADA, La Hacienda Real de Castilla en el siglo XV, La Laguna, 1973, pp. 270 y 273. Ostentó el cargo privado de maestresala del rey.

${ }^{17}$ Una declaración de 1485 sobre los hijos habidos en el matrimonio nos ha transmitido sus nombres: Elvira, don Juan Manuel de Villena, Marina, Mencía de Fonseca, Isabel Manuel, María Manuel, Beatriz y Alfonso Manuel. Los dos últimos fallecieron pronto. AGS, Mercedes y Privilegios, leg. 78 , fol. 35 .

${ }^{18}$ Tras diversos aplazamientos, don Alvaro de Isorna, obispo de Cuenca, y el doctor Arias Maldonado, dictaron sentencia a favor de don Juan Manuel, condenando a su tío, Pedro Manuel, al pago de una indemnización de 320.000 maravedies por los años que había percibido injustamente la totalidad del juro. La violenta reaccion de don Pedro Manuel no sirvió de rada: el juro se asentó en los libros reales a nombre de don Juan Manuel. AGS, Mercedes Privilegios, leg. 78 , fol. 35
Mencía de Fonseca. La familia Fonseca, establecida en Toro desde fines de siglo XIV, procedía de un noble portugués, Pedro Rodríguez de Fonseca, afincado en Castilla tras el desastre de la campaña portuguesa de Juan I ${ }^{19}$ Este personaje, abuelo del embajador que estudiamos aquí, perdió en aquella guerra la tenencia del castillo de Olivenza y otras propiedades en Portugal, y recibió como compensación las tercias del obispado de Badajoz y la villa de Villalba, aunque residió habitualmente en Toro, donde falleció en 1419. Contrajo matrimonio con Inés Díaz Botello y tuvo ocho hijos: Juan Rodríguez de Fonseca, Beatriz Rodríguez de Fonseca ${ }^{20}$, Pedro de Fonse$\mathrm{Ca}^{21}$, Mencía de Fonseca ${ }^{22}$, Leonor Rodríguez de Fonseca ${ }^{23}$, Ruy Pérez de Fonseca, Inés de Fonseca e Isabel de Fonseca ${ }^{24}$.

A la vista de estos datos familiares con sus ramificaciones posteriores se puede entender el grado de relación de don Juan Manuel de Villena con algunos personajes importantes de la corte castellana, y de manera muy especial con Alfonso de Fonseca (+1473) el viejo, arzobispo de Sevilla y Santiago, su primo carnal, cuyo apoyo iba a ser determinante en su carrera diplomática. En cuanto al segundo arzobispo Alfonso de Fonseca $(+1512)$, llamado el joven, hay que decir que don Juan Manuel era tío segundo suyo, aunque no parece que hubiese entre ambos una especial relación. Interesa más destacar el parentesco con Arias Gómez de Silva ${ }^{25}$, casado con su tía Leonor, del que nacería un segundo Arias Gómez de Silva, maestresala de Enrique IV, con el que iba a mantener una especial vinculación afectiva y política. Por otra parte, la familia Fonseca acabó teniendo relaciones de parentesco con otros linajes de Toro, especialmente con los Ulloa y los Portocarrero. Uno de los albaceas testamentarios de don Juan Manuel fue su

${ }^{19}$ Hay abundantes datos familiares sobre los Fonseca en el ms. 9/175 de la Real Academia de la Historia, que utilizamos para ilustrar las relaciones de parentesco. Se trata de un estudio genealógico redactado en 1590 donde se da cuenta de las diversas casas señoriales nacidas o troncadas con los descendientes de Pedro Rodríguez de Fonseca.

${ }^{20}$ Esta Beatriz se casó con Juan Alfonso de Ulioa, consejero de Juan II, y fueron padres del célebre Alfonso de Fonseca "el viejo", arzobispo de Sevilla y Santiago.

${ }^{21}$ Cardenal de Santangel, abad de Valladolid.

${ }^{22}$ Casada con Fernando Manuel de Villena; son los padres del embajador estudiado en este trabajo.

${ }^{23}$ Casada con Arias Gómez de Silva.

${ }^{24}$ Estos tres últimos hijos fallecieron pronto sin haber contraído matrimonio,

${ }^{25} \mathrm{Hijo}$ de Ferrán Gómez de Silva, regidor de Toledo; AGS, Mercedes y Privilegios, leg. 1 , fol. 177 ; leg. 63 , fols. 91,92 y 93 . 
tío Diego López Portocarrero ${ }^{26}$. También figura como primo suyo en el citado testamento Martín de Sosa, perteneciente a otra familia de orígen portugués establecida en Toro ${ }^{27}$.

Hay que añadir un tercer grupo de relaciones de parentesco de don Juan Manuel, el que procede de su esposa, doña Aldonza de la Vega, con la que contrajo matrimonio en 1445. Doña Aldonza era hija de Gome Suárez de Figueroa y Elvira Laso de Mendoza ${ }^{28}$, y por consiguiente, era sobrina del marqués de Santillana. En la escritura de arras, firmada en junio de 1444, se acordó que don Juan Manuel entregase a su futura esposa 3.000 florines de oro, sirviendo de respaldo el juro de 20.000 maravedís que acababa de obtener en el pleito recién ganado contra su tío Pedro Manuel ${ }^{29}$. Actuó como representante de nuestro personaje en aquél acto ${ }^{30}$ su primo Arias Gómez de Silva, maestresala de la reina Isabel de Portugal, ya citado, con quien don Juan Manuel compartía una especial amistad. La dote de Aldonza de la Vega estaba compuesta por algunos bienes de consideración $^{31}$, como la villa y el castillo de Gama (cerca de Santoña) y otros lugares cercanos ${ }^{32}$.

Entre las personas con las don Juan Manuel mantuvo un especial grado de amistad figura don Lope de Barrientos, obispo de Cuenca, que figura como su albacea testamentario, con el que no tenía relaciones de parentesco, aunque sí probablemente de tipo político o profesional, ya que

${ }^{26}$ Diego López Portocarrero, llamado inicialmente Diego de Sousa, era hijo de otro noble exiliado portugués, Gonzalo Rodríguez de Sousa, casado con Mencía Portocarrero. Cfr. Rafael FLORANES Y ENCINAS, Memorias para la historia de la ciudad de Toro, op. cit.. p. ill, con datos tomados de Luis SALAZAR Y CASTRO, Advertencia histórica, pp. 340 y ss.

${ }^{27}$ Ibid.

${ }^{28}$ Argote de Molina emplea el nombre de Juana de la Vega para designarla, pero en la mayor parte de los documentos aparece como Aldonza de la Vega.

${ }^{29}$ Está fechado en Valladolid a 3 de junio de 1444. Para asegurar el pago puntual, la madre de don Juan Manuel, Mencía de Fonseca, aseguraba de su parte otros 16.000 maravedíes que tenía de juro de heredad en las alcabalas de Toro y otros 11.000 en las alcabalas de Cantalapiedra. Parece claro que el patrimonio del futuro embajador no era aún demasiado r-258 $\mathrm{v}$

La escritura de arras se firmó en Valladolid, el 3 de junio de 1444: Salazar, M-1, fol. 258

${ }^{31} \mathrm{La}$ escritura de dote fue otorgada por su madre, Elvira Laso de Mendoza, en Valladolid, el 3 de mayo de 1444; Salazar, M-1, fol. $259 \mathrm{v}-260 \mathrm{v}$.

${ }^{32}$ Se citan los lugares de la Puenterroma, Val, Villacinio y los barrios de Ordeján, San Ibañez y La Puebla, que habían pertenecido a Leonor de la Vega; ibid. La donación de este castillo fue algo posterior; lleva fecha de 8 de abril de 1445 , desde Aguilar; Salazar, M-1, fol. $260 \mathrm{v}-261$ don Lope fue durante bastantes años figura destacada del grupo o partido más fiel a Enrique IV de Castilla.

Las relaciones de parentesco, por vía paterna, materna y matrimonial, demuestran que don Juan Manuel se movía en el círculo más eminente de la alta nobleza castellana, pero con el serio inconveniente de carecer tanto de un título como de fortuna. Sus antepasados directos habían sido siempre hijos segundones, de modo que la realidad material en la que se desenvolvía su familia en Toro no difería demasiado de la de un simple hidalgo. Su padre, Fernando Manuel de Villena, había tratado de impedir el ocaso defintivo de la familia recurriendo a un gesto externo muy propio de la mentalidad nobiliaria: dotó en el monasterio de San Juan y San Pablo de Peñafiel, una de las más célebres fundaciones de su abuelo el infante don Juan Manuel, una capilla para él y sus descendientes ${ }^{33}$. Llama poderosamente la atención la frecuencia de enlaces de parentesco entre familias de orígen portugués, como los Ulloa, los Sosa, los Fonseca, los Silva, incluso la misma estirpe de los Manuel de donde él procedía, algo muy característico del estamento caballeresco de la ciudad de Toro $^{34}$, a pesar de lo cual su trayectoria diplomática quedó orientada hacia la negociación con Francia y no con Portugal.

\section{Primeros años en la Corte de Juan II de Castilla}

Las breves noticias que se han conservado sobre sus años de juventud confirman tres cosas claras: la primera, que don Juan Manuel de Villena vivió y se crió en la Casa real de Juan II de Castilla; la segunda, que en la Corte inició su carrera al servicio del monarca con cargos militares; y

${ }^{33}$ Sobre este convento y el patronazgo de los Manueles ver Elida García García, San Juan y San Pablo de Peñafiel. Economía y sociedad de un convento dominico castellano (I318-15I2), Salamanca, 1986.

${ }^{34}$ Sobre la instalación de linajes portugueses en Castilla ver los trabajos de Emilio MITRE FERNÁNDEZ, La emigración de nobles portugueses a Castilla a fines del siglo XIV, "Hispania", nobiliaria bajo los primeros trastámaras (1369-1406) "III Jornadas Hispano-Portuguesas de nobiliaria bajo los primeros Trastamaras (1369-1406), "In Jornadas Hispano-Portuguesas de Historia Medieval", Sevilla, 1991, actas en prensa). Sobre los linajes de origen portugués en Toro ver Jose Ignacio MORENO NUNEZ, El Regimiento de Toro en el siglo XV, en La ciudad hispánica durante los siglos XIII al XVI, I, Madrid, 1985, pp. 773-783; del mismo, Los
Portocarrero de Toro, linaje de ascendencia portuguesa. Su afincamiento y consolidación en Ponocarrero de Toro, linaje de ascendencia portuguesa. Su afincamiento y consolidacion en 993-1031. 
tercero, que estuvo vinculado a la casa del condestable don Alvaro de Luna, de quien recibió sueldo.

De su crianza y educación junto al rey de Castilla da cuenta inequívoca un testimonio de 1445. En este año los procuradores que asisten a las Cortes de Olmedo, entre los que se encuentra el propio don Juan Manuel de Villena, apoyan con su firma una petición privada de éste último solicitando una ayuda económica para contraer matrimonio. Don Juan Manuel, dirigiendose al rey, se autodenomina como "vuestra criança e fechura", mientras que los procuradores hablan de él como una persona "de vuestra Casa e se aver criado en ella siempre en serviçio vuestro"35. Se cumplía en este caso la costumbre tradicional por la que el monarca criaba en su Casa a un determinado número de vasallos que por razón de parentesco o dignidad social merecían estar en su compañía. Era frecuente que tales criados apareciesen en compañía del rey al llegar a la adolescencia y que permaneciesen junto a él al llegar a la juventud.

Esta fue la puerta de acceso a los primeros cargos, como el de maestresala, que tenía ya en 1445 y que ostentó a lo largo del reinado de Juan II, y a los primeros sueldos, aunque fuesen de un valor bastante humilde. En el mismo documento que acabamos de citar se afirma. claramente que don Juan Manuel no tenía vasallos, de modo que no podía. cobrar estas cantidades que el rey le había asignado para su mantenimiento.

El primer cargo público que tuvo, distinto al meramente privado de maestresala del rey, fue el de procurador de la ciudad de Sevilla en las Cortes de Olmedo de 1445 que acabamos de citar. La importancia de aquellas Cortes es perfectamente conocida, no sólo por haber servido de marco al gran triunfo militar de la realeza frente a los Infantes de Aragón, sino porque en ellas se abordaron reformas de cierta transcendencia, como por ejemplo, la facultad dada a los procuradores para que nombrasen a los recaudadores mayores de los pedidos y monedas, para que pudiesen cobrar de ellos sus honorarios ${ }^{36}$.

${ }^{35} 1445$, febrero, 3. S.l. Albalá de Juan II ordenando, a petición de los procuradores de que se le deben por diversos pedidos y monedas a don Juan Manuel de Villena los maravedís ${ }^{36}$ Cé

${ }^{36}$ César OlIVERA SERRANo, Las Cortes de Castilla y León y la crisis del Reino (1445-1474).
Registro de Cortes, Burgos, $1986, \mathrm{pp} .17-24$.
Su elección como procurador sevillano fue claramente irregular, porque ni era natural de Sevilla ni tenía la menor vinculación con esta ciudad $^{37}$, pero si tenemos en cuenta que durante el gobierno de Alvaro de Luna se difundió la imposición de procuradores entre algunas ciudades castellanas, no sería de extrañar que el Condestable fuese el promotor de su nombramiento ${ }^{38}$. Más lógico hubiera sido, en principio, que don Juan Manuel hubiese ejercido la procuración representando a Toro, lugar de procedencia de su familia ${ }^{39}$.

Don Juan Manuel recibió a lo largo de aquellas Cortes 150 maravedís diarios para su mantenimiento y una merced de 16.000 maravedís ${ }^{40}$. También logró que los dieciseis procuradores restantes -incluído Suero de Moscoso, el segundo procurador de Sevilla- pidieran al rey por escrito que don Juan Manuel cobrara la ayuda para su boda que ya hemos citado, así como otras sumas diversas a cargo del servicio de cinco millones $^{41}$ para sostenimiento de la Casa Real. Entre los firmantes que apoyaban la demanda figuraba Pedro Díaz de Arceo, procurador de Burgos, con quien iba a tener don Juan Manuel bastante relación en el reinado siguiente con ocasión de las embajadas a la Corte francesa.

No sabemos si don Juan Manuel de Villena tuvo oportunidad de nombrar recaudadores de pedidos y monedas en 1445. Lo que sí está claro

${ }^{37}$ Los Manuel de Lando de Sevilla eran, según ARGote DE MOLina, parientes de los Manuel que tratamos aquí, y también de los Cerón, por ser descendientes de Sancho Manuel el hijo menor del infante don Juan Manuel. No parece posible que este lejano parentesco pudiera influir en su nombramiento como procurador. ${ }^{38} \mathrm{La}$ Corona presionó a lo largo de la década a determinadas ciudades para que enviasen
procuradores que no habían sido elegidos en sus respectivos concejos; vid. César OLIVERA SerRano, Las Cortes de Castilla y León, p. 36-37, 42-43 y 66.

${ }^{39}$ Aún se conservan en Toro algunos restos heráldicos que denotan la raigambre de los Manuel en esta ciudad; vid. Rafael FLORANES Y ENCINAS, Memorias para la historia de la ciudad y tierra de Toro, (reed) Valladolid, 1994.

${ }^{40}$ César Olivera Serrano, Las Cortes de Castilla y León, doc. 6, p. 187.

${ }^{41}$ Los procuradores habían concedido a Juan II en 1444 un servicio de 10 millones de maravedíes para sostenimiento de la Casa Real, divididos en dos pagas de 5 millones cada una; la segunda se debía cobrar en 1445 , y sobre ésta última debieron pagarse a don Juan Manuel sus cantidades ya que era maestresala del Rey y miembro de su Casa; el texto del otorgamiento SERRANo, Las Cortes de Castilla y el poder real (1431-1444), "En la España Medieval", I1 (1988), p. 259. 
es que Juan II le concedió durante estas mismas Cortes algunos excusa$d o s^{42}$. Salvando las distancias respecto a lo que recibieron otros Grandes don Juan Manuel también salió beneficiado del reparto de bienes y rentas subsiguientes a la batalla de Olmedo.

Después de contraer matrimonio en 1445 con Aldonza de la Vega, Ia actividad principal de don Juan Manuel continuó al servicio del rey Durante la guerra que se sostuvo entre 1447 y 1450 contra don Juan de Navarra en torno a las fortalezas de Atienza, Torija, Peña de Alcazar y otras plazas limítrofes entre Aragón y Castilla, don Juan Manuel estuvo al mando de una compañía que se encargaba de labores de vigilancia en la zona de Atienza y Berlanga. En su testamento, redactado casi veinte años después, el propio don Juan Manuel nos desvela algunos de los desmanes cometidos por él y por su tropa en aquellas fechas:

Manden una o dos personas de recabdo a las villas de Atiença y Berlanga, y hayan pesquisa sobre algunas personas que recibieron daño estando en la guerra e fueron acusados por sospechosos de ser navarros, segund mas largo sabe Juan de Rosales, que era mi alguasil, de los quales yo ove algunos provechos; e por los tales singularmente dapnificados quiero repartir dies mil maravedís, aviendo primera mente respecto a una dueña viuda de Verlanga a la qual fueron tomadas doze azemilas en el monte de Retortillo, e aquesta debe aver mil maravedís, pues yo compré las azemilas a los que las tomaron. (...) Por quanto otros males general mente fueron fechos en la dicha guerra por la gente que yo tenía en mi capitanía, de los quales yo como capitan ove quinto e di lugar sueltamente, e no bast de los memoria para satisfaçer, mando que generalmente se den a todos los $\underset{43}{\operatorname{vezinos}}$ de Atienza e Verlanga e sus tierras (...) otros diez míll maravedís

Antes de su muerte, en recuerdo de aquella campaña ya lejana, don Juan Manuel ordenó colocar sobre su sepulcro el estandarte que había usado

${ }^{42}$ El 18 de marzo de 1445 Juan II le concede 8 excusados que tenía puestos por salvado don Lope de Mendoza, arzobispo de Santiago, ya difunto. El 27 de abril de 1445 le concedió otros 14 excusados de monedas que habia tenido en Fregenal de la Sierra fray Juan de Morales, bispo de Badajoz. AGS, Mercedes y Privilegios, ieg. 10, fol. 132.

${ }^{43}$ Testamento de don Juan Manuel de Villena, otorgado el 10 de mayo de 1459 en el castillo de Tineo; RAH, Salazar, M-1, fol. 251-254v. en la frontera de Aragón ${ }^{44}$. Ni él ni su compañía combatieron directamente las plazas fuertes de la frontera, cuando las tropas reales, dirigidas por Juan II y don Alvaro de Luna, atacaron violentamente Atienza ${ }^{45}$. Es muy probable que hasta el final del reinado de Juan II siguiera ejerciendo la carrera de las armas, porque en 1453 tenía en los libros del rey 46.500 maravedís para sostener 31 lanzas $^{46}$.

La Crónica de don Alvaro de Luna asegura, por otra parte, que don Juan Manuel de Villena percibió acostamiento del Condestable, aunque no indica la cuantía ni la duración ${ }^{47}$. No hay mas información ántes del nuevo reinado, pero todos los datos anteriores coinciden en una misma dirección: don Juan Manuel estuvo siempre en las mismas empresas que dirigió don Alvaro de Luna. Sin embargo no hay indicios que aclaren su posición personal en las tramas políticas que provocaron la caída del Condestable. Es razonable pensar que se mantuviese al margen del drama, teniendo en cuenta su escaso poder personal, aunque no hay que perder de vista que nada más comenzar el nuevo reinado aparece don Juan Manuel muy bien relacionado con el nuevo equipo de gobierno.

\section{AL SERVICIO DE ENRIQUE IV.}

\section{LAS EMBAJADAS A FRANCIA (1455-1458)}

La desaparición de Juan II de Castilla en julio de 1454 y la subida al trono de su hijo Enrique IV significó para don Juan Manuel de Villena un cambio importante en su carrera: iba a convertirse en uno de los embajadores castellanos más activos en los primeros años del nuevo reinado. Probablemente don Juan Manuel había mantenido buenas relaciones con don Enrique mientras éste fue Príncipe de Asturias, porque en 1455 ostentaba un cargo privado dentro de su Casa de cierta relevancia, el de guarda mayor,

${ }^{44 n}$... sea por mitad negro y blanco con una cruz florada como las de Calatrava, la qual sea asi mismo blanca e negra de Santo Domingo, tocando lo negro sobre lo blanco e lo blanco sobre lo negro, e çerca deste mi estandarte pongan una tarja de mis armas e la cota de armas que está

${ }^{45}$ Un estudio de los asedios en Francisco Layna SERrano, Historia de la villa de Atienza, Madrid, 1945. No aparece citada la capitanía de don Juan Manuel.

${ }^{46}$ AGS, Contaduría del Sueldo, leg. 1, s. fol (mazo de don Juan Manuel).

${ }^{47}$ Crónica de don Alvaro de Luna, Condestable de Castilla, Maestre de Santiago, ed. de Juan de Mata CARRIAZO, Madrid, 1940, p. 447 
con el que se le va a citar a lo largo de sus misiones diplomáticas futuras. Su antiguo cargo de maestresala bajo Juan II desaparece. Por otro lado, algún tipo de contacto tuvo que mantener con la reina doña Juana de Portugal, casada con Enrique IV en 1455, aunque de momento es difícil de precisar su alcance. En dicho año, don Juan Manuel recibe de la reina un juro de 10.000 maravedís ${ }^{48}$. Sea cual sea el motivo de su concesión, el dato confirma una estrecha relación con los nuevos soberanos.

Las crónicas de la época recogen algunos detalles interesantes acerca de los apoyos y amistades de nuestro personaje en aquél instante. La crónica de Diego de Valera se limita a citar brevemente el hecho de su nombramiento como embajador ${ }^{49}$. La Crónica Castellana añade que don Juan Manuel era ya en ese momento miembro del Consejo Real $1^{50}$. Alonso de Palencia es más explícito: afirma que antes de decidirse la composición de la embajada que iba a llevar a Carlos VII de Francia la noticia del cambio de reinado en Castilla, se presentaron dos candidaturas opuestas. Una la encabezaba don Alfonso de Velasco, hermano del conde de Haro, y la otra era la de don Juan Manuel. A este último le apoyaba don Juan Pacheco, favorito del nuevo rey, quien aprovechó su influencia para que la designación recayera en su defendido ${ }^{51}$. Alonso de Palencia reconoce la nobleza de su linaje, pero acusa a don Juan Manuel de ser indocto y añade finalmente que por este motivo tuvo que ser acompañado en aquella embajada por Fortún Velázquez de Cuéllar, protonotario apostólico y deán de la iglesia de Segovia $^{52}$, y por el doctor Alfonso Alvarez de Paz. Concluye el cronista Palencia su crítico comentario añadiendo que "con su falta de instrucción, quitó gran autoridad a su elocuencia"53. El desprecio que rezuman estas breves frases contra don Juan Manuel se deben, probablemente, al rencor

48 1455, noviembre, 15. Avila: privilegio de 30.000 maravedíes de juro, de los que 10.000 proceden de una donación de doña Juana de Portugal. AGS, Mercedes y Privilegios, leg. 78 ,
fol. 25 .

49 Juan de Mata CARRIAzo (ed), Memorial de diversas hazañas (Crónica de Enrique IV), (Colección de Crónicas Españolas, IV), Madrid, 1941, p. 7.

${ }^{50}$ María Pilar SÁNCHEZ PARRA (ed), Crónica anónima de Enrique IV de Castilla, 1454-1474 (Crónica Castellana), II, Madrid, 1991, pp. 9-10.

${ }^{51}$ Antonio PAZ Y MELIA (ed), Crónica de Enrique IV por Alfonso de Palencia (BAE tomo CCLVII, vol. I), Madrid, 1973, pp. 63-64.

${ }^{52}$ Sobre este personaje ver Hilario SANZ Y SANZ, Catálogo de la colección diplomática

${ }^{53}$ Ver nota 51. que Palencia sentía contra Enrique IV y Juan Pacheco; además hay que tener en cuenta que el mismo Palencia también ejerció funciones diplomáticas a lo largo de su vida, para las que se sentía mucho más preparado. Por consiguiente, sus opiniones hay que tomarlas con precaución, mas bien como un desahogo de autosuficiencia. Si don Juan Manuel hubiese demostrado una excesiva incompetencia en su oficio de embajador, lo más probable es que no hubiera vuelto a recibir nuevos encargos diplomáticos una vez concluída su primera misión en Francia. Pero los recibió, y no sólo para cumplir misiones protocolarias.

Dejando al margen las opiniones peyorativas de Palencia, no hay que perder de vista un dato útil: la buena relación mantenida con los nuevos dirigentes de la Corte castellana, como Juan Pacheco, o especialmente con su primo el arzobispo Alfonso de Fonseca, muy influyente también en los primeros años del reinado de Enrique IV. En una credencial redactada por el arzobispo en 1457 a Carlos VII de Francia, presenta a don Juan Manuel como "frater consanguineus meus" 54 . Esta carta credencial demuestra, por otra parte, que Fonseca debía tener a su cargo los asuntos diplomáticos con Francia en el seno del Consejo Real, de modo que la elección de don Juan Manuel permitía al influyente prelado contar con una persona de su confianza. Junto a esto hay que destacar que en una misión diplomática de corte protocolario, Enrique IV escogió a una persona que reunía parentesco real, aunque fuese lejano, y una lealtad siempre preferible a la de un miembro de la alta nobleza. Don Juan Manuel no tenía otros méritos personales que las expuestas; no podía apoyarse en su experiencia diplomática anterior porque no la tenía. Con Juan II y Alvaro de Luna había había desempeñado cometidos militares y cortesanos, incluyendo el oficio procurador de Cortes. Ahora era designado para una misión diplomática de cierto nivel por decisión de Enrique IV, de Juan Pacheco y, probablemente, del arzobispo Alonso de Fonseca.

El equipo diplomático formado por don Juan Manuel, Fortún Velázquez de Cuéllar y Alfonso Alvarez de Paz actuó entre 1455 y 1457 en diversas negociaciones con Francia. Aquí aparece otro rasgo interesante de la diplomacia castellana: la formación estable de grupos de embajadores que

${ }^{54} 1457$, febrero, 7. Palencia: Carta de creencia otorgada por el arzobispo Alonso de Fonseca al rey de Francia, Carlos VII, pidiéndole que escuche lo que le ha de comunicar su primo don Juan Manuel de Villena, embajador del rey de Castilla. Biblioteca Nacional de París, Mss.
Latins, m. 6024, no 1 . 
repiten en varias ocasiones sus viajes. En este caso la embajada se compone de un noble, un clérigo y un letrado. Se aprecia un cierto equilibrio en la composición, probablemente con el fin de aunar prestigio social, elocuencia, conocimiento del derecho y tal vez de lenguas, puesto que el latín predomina como lengua oficial diplomática entre ambas cortes. Daumet y Suárez Fernández han explicado el alcance político de estas embajadas ${ }^{55}$. A los datos ya expuestos por estos historiadores se pueden añadir otros hasta ahora desconocidos que sirven para conocer mejor el resultado de aquellas negociaciones.

El primer viaje diplomático tuvo lugar en una fecha incierta que se sitúa entre el advenimiento de Enrique IV (julio de 1454) y las últimas semanas del año 1454. Don Juan Manuel y sus dos acompañantes viajaron a Francia para comunicar oficialmente la muerte de Juan II y la subida al trono de su hijo, tal como se ha dicho, pero tuvieron que realizar un segundo viaje muy poco después puesto que los poderes que habían recibido en la Corte de Castilla sólo eran válidos para transmitir la noticia y no para confirmar la alianza franco-castellana ${ }^{56}$. Carlos VII de Francia tenía un especial interés en renovarla y por ello tuvo que enviar una embajada a Castilla; los embajadores franceses llegaron a la Corte castellana en plenas Cortes de Córdoba (marzo-junio de 1455), donde presenciaron el matrimonio del rey con Juana de Portugal (mayo). La confirmación de la alianza francocastellana tuvo lugar el 10 de julio de $1455^{57}$.

La segunda misión diplomática encomendada a don Juan Manuel, Fortún Velázquez de Cuéllar y Alfonso Alvarez de Paz se desarrolló en 1456. Tras recibir los poderes del rey en el mes de enero ${ }^{58}$ y la carta de

${ }^{55}$ Geaoges DAUMET, Étude sur l'alliance de la France et de la Castille au XIVe et au XVe

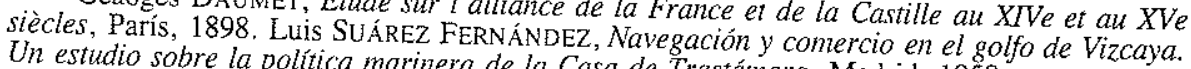
${ }^{56}$ Geores lastámara, Madrid, 1958. ${ }^{56}$ Georges DAUMET, Étude sur l'alliance, p. 94. Juan TORRES FONTES (ed), Estudio sobre
la crónica de Enrique IV del doctor Galindez de Carvajal, Murcia, 1946, pp. 150-151, Luis AREZ FERNANDEZ, Navegación y comercio, p. 116.

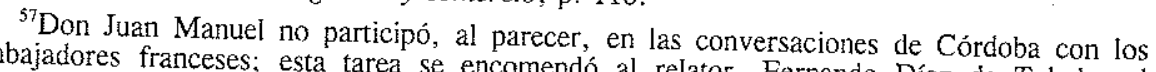
marqués de Santillana y al marqués de Villena al relator, Fernando Díaz de Toledo, al exteriores; Georges DAUMET, Étude sur l'alliance, verdaderos responsables de los asuntos ${ }^{58}$.

DAUMET, Etude sur l'alliance, pp. 248-251. presentación en febrero ${ }^{59}$, se pusieron en camino con el fin de participar en lá Conferencia de Gannat con los representantes del rey de Francia. La complejidad de esta misión fue mayor que las anteriores; no se trataba de un contenido meramente protocolario, sino de una negociación compleja que afectaba a numerosos asuntos bilaterales entre Castilla y Francia. El margen de autonomía para la decisión de los embajadores parece bastante más ámplio. Aunque no se ha conservado el texto oficial de lo acordado en esta conferencia, conocemos el contenido de las propuestas castellanas que defendieron don Juan Manuel y sus compañeros ${ }^{60}$. Las más importantes se referían a la conservación del régimen de salvoconductos que los comerciantes castellanos y franceses empleaban para viajar a Inglaterra. También proponían la conservación de los privilegios que disfrutaban los castellanos en Francia desde el pasado, y de modo especial, los de Burdeos y Bayona, porque tras la reconquista francesa de Gascuña no se habían respetado. A todo esto se añadía el problema de los roces crecientes en Fuenterrabía. La última de las propuestas castellanas iba a marcar de modo especial la labor de don Juan Manuel en los años posteriores: consistía en solicitar al rey de Francia el perdón para el conde Juan V de Armagnac, que había perdido en 1455 sus dominios en el sur de Francia al ser invadidos por el ejército real de Carlos VII. El conde había logrado escapar y se hallaba refugiado en Bielsa (Aragón), pendiente del juicio que se seguía contra él en el parlamento de París; se le acusaba de rebelión y de otros delitos sin cuento ${ }^{61}$.

Para Castilla era importante defender la causa del conde de Armagnac. Juan II de Castilla y Juan IV de Armagnac habían mantenido años atrás una estrecha colaboración que se había materializado en un vínculo vasallático estable, de gran utilidad en caso de guerra contra Aragón y sus aliados ${ }^{62}$. En 1456 Enrique IV deseaba contar otra vez con su aliado francés para defender la causa del Príncipe de Viana, amenazada por la

${ }^{59}$ Fechada en Segovia, el 3 de febrero de 1456; publ. por Luis SUÁREZ FERNÁNDEZ, Navegación y comercio, p. 215.

60Publ. por SuÁrez Fernández, Navegación y Comercio, doc. 37.

${ }^{6}$ Charles de SAMARAN, La Maison d'Armagnac et les dernières luttes de la Feodalité dans le Midi de la France, París, 1908 , pp. 113 y ss.

${ }^{62}$ En 1434 el rey de Castilla había concedido el condado de Cangas y Tineo a Juan IV. La relación vasallática entre ambos en César OLIVERA SERRANO, Los condes de Armagnac y la diplomacia castellana del siglo XV (1425-1474), "En la España Medieval", 16 (1993), pp. 189 - 
alianza de Juan II de Aragón y Gastón IV de Foix ${ }^{63}$ establecida un año ántes. Don Carlos de Viana y Juan V, además de ser primos carnales, eran aliados formales desde 1451. Para la diplomacia castellana, Gannat no era simplemente una conferencia de contenido mercantil, sino que era también una ocasión importante para asegurar alianzas frente a Aragón ante el problema de Navarra. La mejor prueba de esto último está en que el Príncipe de Viana también mandó sus representantes a Gannat para defenderse de las acusaciones de anglofilia que le habían lanzado los condes de Foix.

Gannat marca el fin de las buenas relaciones entre Castilla y Francia ${ }^{64}$, pero no sólo por motivos mercantiles. Francia no se comprometía en las iniciativas castellanas destinadas a defender la causa del Príncipe de Viana. Por su parte, Castilla se empeñaba en defender a un conde cuya rebeldía hacia el rey de Francia era proverbial. Había demasiadas trabas para que ambas monarquías siguieran manteniendo puntos de vista comunes, aunque todavía no se habían problemas de mayor calado. En los seis años siguientes se iba a pasar de la frialdad a la hostilidad.

Con ocasión de la conferencia de Gannat, don Juan Manuel estableció una relación personal muy estrecha con Juan $\mathrm{V}$ de Armagnac: desde 1456 se convirtió en el principal agente del conde para los asuntos de Castilla y hasta el año 1459 se encargó personalmente de gestionarlos. Su empeño obedece a razones de interés personal, como veremos en seguida. Juan V necesitaba la ayuda de Enrique IV para recuperar el favor de Carlos VII junto con la restitución de los bienes confiscados. Por otra parte, pesaba sobre él una sentencia de excomunión papal, y no era fácil mover la causa en Roma sin el apoyo de algún monarca occidental. Por último, le hacía falta recibir los ingresos económicos que tenía asignados en la hacienda real castellana. Don Juan Manuel parecía ser la persona más adecuada, porque gozaba de la confianza del rey castellano y del equipo nobiliario que le rodeaba. Durante aquellos años, en los que llegó a viajar expresamente a la ciudad de Aviñón para entrevistarse con Juan $\mathrm{V}$ de Armagnac, don Juan Manuel asumió una gran dósis de iniciativa personal. Ninguno de sus dos compañeros de embajada tomó parte en tales asuntos, y esto podría ser un

${ }^{63}$ Juan REGLÁ CAMPISTOL, La cuestión de los Pirineos a comienzos de la Edad Moderna. El intento imperialista de Gastón de Foix, "Estudios de Historia Moderna", I (1951), pp. 1-31. ${ }^{64}$ Navegación y comercio, p. 118. indicio para pensar que cada embajador se especializaba en diferentes temas concretos que dominaba por una razón especial.

Don Juan Manuel acudió a Bielsa en noviembre de 1456, donde se refugiaba el exiliado Juan $V$, que esperaba con impaciencia el resultado de su proceso penal en París. Ambos acordaron que el condado de Cangas y Tineo, propiedad del francés, fuese administrado por el embajador castellano; quedaba revocada desde ese instante la lugartenencia que había tenido hasta entónces Pedro Díaz de Arceo, hermano de Iñigo Díaz de Arceo $^{65}$.

Aunque no sabemos en qué momento anterior habían entrado en contacto el conde de Armagnac y Pedro Díaz de Arceo, no es demasiado arriesgado suponer que la relación procedía de los contactos que tenía en Francia esta gran familia de mercaderes burgaleses ${ }^{66}$. Lo que sí parece claro es que los Arceo habían prestado una elevada suma de dinero a Juan V (más de 4.000 doblas) y que la garantía de su devolución había quedado fijada en las rentas del condado de Cangas y Tineo ${ }^{67}$. El gran prócer de la familia Díaz de Arceo era Iñigo, que por aquellas fechas desempeñaba el cargo de Bolsero de Carlos VII y era además su embajador en Castilla; tras la conferencia de Gannat había sido nombrado por Enrique IV responsable de la firma de los salvoconductos castellanos ${ }^{68}$; él encarnaba la tradicional amistad franco-castellana. Su hermano Pedro, alcalde mayor de Burgos hasta 1462, venía desempeñando desde 1445 regularmente la procuración de Cortes por su ciudad: había coincidido con don Juan Manuel en las Cortes de Olmedo. El traspaso de la lugartenencia de Cangas y Tineo a don Juan Manuel perjudicó seriamente a Pedro Díaz de Arceo, que se quedaba sin la renta fija para recuperar el dinero que le debía Juan V. Por este motivo don Juan Manuel, al tomar posesión de la lugartenencia en enero de 1457 , se comprometió a dejarle cobrar las rentas atrasadas del condado así como otras

${ }^{65}$ En Bielsa se firmó un documento el 10 de noviembre de 1456 , por el que se nombraba a don Juan Manu como lun dertiente y administrador del condado; RAH, Salazar, M-1, fol. 241 T-241 v; publicado en César OLIVERA, Los condes de Armagnac, doc. 2.

${ }^{66}$ Sobre los Arceo ver Yolanda GUERRERO NAVARRETE, Organización y gobierno en Burgos durante el reinado de Enrique IV de Castilla, 1453-1476, Madrid, 1986, pp. 156-160; también Betsabé CAUNEDO DEL POTRO, Mercaderes castellanos en el golfo de Vizcaya (1475-1492), Madrid, 1983, pp. 263-264.

${ }^{67}$ César Olivera, Los condes de Armagnac, doc. 3. 92. 
cantidades asentadas en los libros reales hasta la satisfacción plena de la deưda ${ }^{69}$. Don Juan Manuel dejó como lugarteniente suyo en el condado asturiano a Gonzalo Fernández de Merodio ${ }^{70}$.

Las últimas misiones diplomáticas de don Juan Manuel en Francia prosiguieron a lo largo de 1457. Enrique IV le envió a comienzos de dicho año ${ }^{71}$ en compañía del doctor Alfonso Alvarez de Paz para tratar de poner en paz entre Carlos VII y su hijo el Delfín: nada consiguieron ${ }^{72}$. Tampoco lograron resultados favorables en otras gestiones mercantiles que se les había encomendado ${ }^{73}$. Este parece ser el ocaso de su vida como diplomático. No hay más noticias sobre sus viajes a Francia. Durante los dos años siguientes -1458 y 1459- don Juan Manuel residía en Castilla y todavía se ocupaba de mover influencias para que el rey de Francia levantara el castigo contra el conde de Armagnac ${ }^{74}$. En los libros de la Hacienda castellana reaparece el pago de las lanzas que antaño había tenido ${ }^{75}$.

En aquellos dos años se deterioró más la alianza franco-castellana, y no es de extrañar que los gestores que habían participado años atrás en su mantenimiento acabaran pasando a un segundo plano. Este fue, desde luego, el destino de don Juan Manuel. Su cese de actividad diplomática le condujo a un retorno paulatino hacia el servicio del rey en la Corte. Por una carta escrita al conde de Armagnac en octubre de 1459 sabemos que Enrique IV ya no le destinaba a misiones de rango diplomático, sino que en su lugar

${ }^{69}$ Pedro Díaz de Arceo entregó la tenencia a don Juan Manuel el 29 de enero de 1457, en Palencia; César OLIVERA, Los condes de Armagnac, doc. 3 .

${ }^{70} \mathrm{El}$ poder para ejercer la lugartenencia en nombre suyo y como apoderado del conde de Armagnac, fue otorgado en Palencia el 4 de diciembre de 1457; RAH, Salazar, M-1, fol. 241v.

${ }^{11} 1457$, enero, 30; Palencia: Carta de creencia de Enrique IV para Carlos VII de Francia; cit. por DAUMET, Etude sur l'alliance, p. 98 . Otra carta de creencia, firmada en Palencia po su primo Alonso de Fonseca, el 7 de febrero de 1457: Biblioteca Nacional de París, Mss. Latins, m. 6024, n ${ }^{\circ}$

${ }^{72}$ Juan de Mata CARrIazo (ed), Memorial de Diversas Hazañas. Crónica de Enrique IV, por Mosén Diego de Valera. Madrid, 1941, p. 47.

${ }^{73}$ DAUMET, Etude sur l'alliance, pp. 98-100 y SUÁREZ FERNANDEZ, Navegación y comercio, pp. 118-119.

${ }^{74} \mathrm{Ver}$ la carta de Enrique IV al conde de Armagnac en septiembre de 1459 informando de las gestiones ante Carlos VII y el Papa en favor de su causa; publ. en OLIVERA, Los condes de Ammagnac, docs. 4 y 5 .

${ }^{75} 1458$, diciembre, 22; Medina del Campo: cédula de Enrique IV ordenando el pago de 46.000 maravedís a don Juan Manuel para el sostenimiento de 31 lanzas, en las rentas del condado de Cangas y Tineo. RAH, Salazar, M-1, fol. 243. aparecía ahora su primo Arias Gómez de Silva ${ }^{76}$. A partir de este momento se-rompieron las relaciones estables entre don Juan Manuel y Juan V de Armagnac.

A la vista de todo lo anterior; se deduce que don Juan Manuel desempeñó sus misiones diplomáticas con sentido doble, es decir, como embajador de Enrique IV ante la Corte francesa y como representante o gestor del conde de Armagnac en Castilla. Al calor de esta relación de ida y vuelta, logró unos beneficios personales que no debieron obstaculizar su función principal. No hay el menor rastro de secreto en su comportamiento ni tampoco parece que Enrique IV pusiese reparos a esta doble actividad. Existe, en este sentido, un cierto parecido con Iñigo Díaz de Arceo. Por otro lado se demuestra una vez más que la dirección de la diplomacia castellana correspondía al Consejo real, y de modo más específico, a algunos personajes especialmente influyentes. En este marco hay que situar la elección de los embajadores que, como don Juan Manuel, estaban relacionados con ese reducido número de personas que tomaban las decisiones importantes. Parece claro que la relación más intensa y determinante con este grupo fue la de parentesco; don Juan Manuel la tenía en grado lejano con el rey y muy cercana con el arzobispo Fonseca y con el embajador Arias Gómez de Silva. Junto al parentesco, también tuvo su importancia la coincidencia en temas o asuntos con otros personajes de prestigio: don Juan Manuel coincidió con la influyente familia Arceo al menos en dos ocasiones; la primera en 1445, con ocasión de las Cortes de Olmedo, y la segunda en 1457 a raíz de la entrega del condado de Cangas y Tineo.

Las cartas credenciales que se han conservado junto con los documentos que recogen las instrucciones de lo que se debía gestionar en Francia, aún siendo escasos, demuestran que los márgenes de libertad e iniciativa personal de un embajador como don Juan Manuel variaban bastante de unas embajadas a otras. En la primera misión diplomática que desempeñó predomina el encargo verbal para transmitir una información a la otra parte. en de un mandadero. Ia En este sentido, su cometido más bien parece esta regla. En cambio, se observa un ámplio márgen de iniciativa personal en to gestión de los asuntos del conde de Armagnac en Castilla. De esta relación con Juan V se han conservado las únicas cartas escritas por don Juan Manuel

${ }^{76}$ Publ. en Olivera, Los condes de Amagnac, doc. 6. 
en aquellos años. En alguna de ellas se puede observar algún detalle de interés, como la importancia que tenía en la Corte de Castilla la presencia de alguna persona que "moviera" los hilos para que un asunto determinado no acabase en el olvido.

\section{LA COMPLICADA ADQUISICIÓN DE UN SEÑORÍO: DEL CONDADO DE CANGAS Y TINEO AL SEÑORÍO DE BELMONTE DE CAMPOS}

A lo largo de los años dedicados a la actividad diplomatica, don Juan Manuel hizo un gran esfuerzo para mejorar su posición social y económica. La adquisición de un señorío era una meta necesaria para cualquier noble de su generación y especialmente para él, ya que pertenecía a una ilustre familia venida a menos. Desde mediados de siglo la mayor parte de los sueldos que la Corte pagaba se fijaban en los recaudadores encargados de cobrar algunas rentas reales como alcabalas, tercias o pedidos de Cortes. Por consiguiente, la propiedad sobre un señorío era una de las pocas garantías de percibir regularmente los acostamientos de lanzas, raciones o quitaciones. Tener vasallos significaba algo más que un mérito social. Ya se encargaron de recordarselo al rey los procuradores de las Cortes de Olmedo cuando afirmaban que don Juan Manuel no tenía vasallos, y por tanto, no tenía forma de cobrar sus primeros sueldos de la Corte.

Un camino frecuente recorrido por aquellos que estaban empeñados en alcanzar la posesión de un señorío pasaba por la merced real. Sin embargo Enrique IV jamás se lo otorgó a don Juan Manuel, ni siquiera en pago por los servicios prestados como diplomático. Este monarca, tan pródigo en ocasiones con algunoș hidalgos de oscura procedencia, no se dignó concederle ningún título o señorío, a pesar de que su linaje tenía un prestigio difícil de igualar. Tuvo que ser el propio don Juan Manuel, a través de tortuosas maniobras, el encargado de obtenerlo entre los ya existentes en Castilla, aunque con un serio inconveniente: carecía de fortuna. Sin medios económicos la meta era poco menos que imposible, porque sin merced real no había otro camino que el de la compra, y los precios que se pagaban por los señoríos significaban un desembolso muy considerable. A pesar de todos estos inconvenientes lo intentó con gran empeño a través del único campo en donde podía tomar iniciativas: el de la diplomacia.
La oportunidad llegó en 1456, cuando en sus primeros viajes a Francia trabó contacto con el conde de Armagnac, Juan V, titular del condado asturiano de Cangas y Tineo, quien le nombró lugarteniente, tal como hemos visto ya. Este condado había pertenecido en el pasado a distintas familias y había sido objeto de algunos litigios. El primer propietario había sido de don Enrique de Villena, el célebre literato y nigromante, que no tenía ningún lazo familiar con nuestro don Juan Manuel de Villena, a pesar del apellido ${ }^{77}$. Enrique III había constituído este condado para compensarle de la pérdida del Marquesado de Villena; pero lo poseyó pocos años, porque a comienzos del siglo XV Cangas y Tineo aparece en manos del Adelantado Pedro Suárez de Quiñones y más tarde en las de su sobrino Diego Fernández de Quiñones. En 1434 Juan II de Castilla ordenó a los Quiñones restituir a la corona el condado ${ }^{78}$, y poco después, en este mismo año, el rey se lo concedió a Juan IV de Armagnac. A la muerte de éste último en 1450, el condado pasó a su hijo, Juan V. En los primeros años cuarenta los Quiñones ocuparon por la fuerza el condado, hasta que en 1446 el Príncipe de Asturias lo recuperó para sí. Al morir Juan IV de Armagnac en 1450, su hijo Juan V se convirtió en el nuevo conde de Cangas y Tineo $^{79}$.

No hay constancia de que Juan $\mathrm{V}$ de Armagnac llegara a pisar una sola vez su condado asturiano, aunque sí nombró lugarteniente y justicias. Le sirvió ante todo para cobrar algunas rentas en Castilla situadas en él, y sobre todo, lo utilizó como garantía del préstamo ya citado que recibió de la familia Arceo. Aprovechando el relativo desinterés de Juan V por su condado, don Juan Manuel trató con él un pacto que iban a concluir con su traspaso a manos del embajador castellano.

Entre los acuerdos que don Juan Manuel hizo con Juan V de Armagnac en Bielsa (1456) figuraba uno de especial interés: en el caso de que Juan $\mathrm{V}$ incumpliese sus compromisos, la titularidad del condado de Cangas y Tineo pasaría a su propiedad. Y esto fue lo que ocurrió poco tiempo después: en agosto de 1457 , desde Aviñón, Juan V traspasaba la

${ }^{7}$ Don Enrique de Villena era hijo de don Pedro de Aragón (hijo de Alfonso de Aragón, marqués de Villena) y Juana (hija bastarda de Enrique II y Elvira Iñiguez de la Vega). Sobr este personaje ver Enrique COTARELO Y MORI, Don Enrique de Villena. Su vida y obras,

${ }^{78}$ Fernán PÉrEZ DE GuZMÁN, Crónica de Juan $I I$, cap. v de 1434

${ }^{79}$ Olivera, Los condes de Armagnac, p. 197-198. 
propiedad del condado a don Juan Manuel y a comienzos de 1458 el condado de Cangas y Tineo ya estaba en sus manos. El cambio de propiedad fue autorizado expresamente por Enrique IV ${ }^{80}$.

La propiedad sobre el condado asturiano debía ser dudosa por razones diversas, porque ese mismo año don Juan Manuel decidió cambiarlo por el señorío de Belmonte de Campos a doña Inés de Guzmán, condesa de Trastámara, teniendo que pagar además a la condesa una suma de 400.000 maravedís ${ }^{81}$. El traspaso efectivo tardó algún tiempo en producirse, porque el testamento de don Juan Manuel se redactó en el castillo de Tineo el 10 de mayo de $1459^{82}$. El interés de los Quiñones por este condado asturiano venía de mucho tiempo atrás ${ }^{83}$.

La última complicación jurídica se produjo en 1462, cuando Enrique IV decidió anular el traspaso de propiedad hecho entre Juan V de Armagnac y Juan Manuel seis años antes, probablemente para facilitar a su aliado francés el cobro de cantidades que aún tenía asignadas en los libros de la Hacienda castellana ${ }^{84}$. Es difícil saber si una decisión real como esta fue el resultado de una ruptura entre don Juan Manuel y Enrique IV. A pesar de todo, la propiedad efectiva de Belmonte de Campos no fue perturbada por esta decisión real. Los descendientes de don Juan Manuel fueron titulares del señorío sin el más mínimo estorbo.

\section{CONCLUSIÓN}

Al sobrevenirle la muerte en 1462 don Juan Manuel de Villena había alcanzado una série de metas personales y familiares de cierta importancia

${ }^{80}$ La autorización de Enrique IV no tiene fecha; RAH, Salazar, M-2, fol. 197-201v. Cabe la posibilidad de que se trate de una falsificación para justificar la propiedad de don Juan

${ }^{81} 1458$, abril, 10; Valladolid: escritura de trueque entre ambos. Doña Inés afirma que ella y su primer esposo, Alonso Pérez de Vivero, lo habían comprado a Pedro Sarmiento, repostero mayor de Juan II. RAH, Salazar, M-1, fol. 259.

${ }^{82}$ RAH, Salazar, M-1, fol. 251-254v

${ }^{83}$ César Alvarez Alvarez, El condado de Luna en la baja Edad Media, León, 1981, pp. 246-247

841462, marzo, 24; Madrid: Cédula de Enrique IV anulando el traspaso a petición de Juan V de Armagnac; AGS, Diversos de Castilla, leg. 9, núm. 52, publ. en OLIVERA, Los condes de Armagnac, doc. 7. gracias a la diplomacia, aunque no llegasen ni con mucho a los niveles que antaño había disfrutado el linaje de los Manuel. Su hijo mayor, llamado igualmente Juan Manuel de Villena, mantuvo la tradición paterna en la carrera diplomática y llegó a ser un embajador muy conocido durante el reinado de Felipe I el hermoso y Carlos I, llegando a ser consejero real y miembro de la Orden del Toisón de Oro ${ }^{85}$.

A la luz de la información de los papeles contables de Simancas, de su testamento y de otros documentos conservados en la Academia de la Historia, podemos hacernos una idea bastante acertada de los bienes que poseyó el embajador a lo largo de su carrera política y especialmente al final de su vida. El objetivo primordial, la consolidación del linaje mediante la adquisición de un señorío, había sido alcanzado, aunque no fundó mayorazgo sobre Belmonte de Campos. Por desgracia no es posible calcular el valor de este señorío, porque se obtuvo mediante trueque con el de Cangas y Tineo, pero no cabe duda de que fue la inversión más importante de su vida. Sin embargo conocemos mejor sus ingresos ordinarios de la Corte (juros, sueldos) que dan idea de su capacidad económica habitual. El resúmen de sus ingresos expresados en maravedís es como sigue:

-Merced de por vida: 58.200 anuales, además de 10.500 para una lanza de su criado.

-Tierra para 61 lanzas: 46.500 anuales.

-Quitación: 30 maravedís diarios (10.800 anuales)

-Quitación por Guarda mayor: 50 maravedís diarios (18.000 anuales).

-juro ganado en pleito contra su tío Pedro Manuel: 20.000 anuales. -juro de la reina Juana de Portugal: 10.000 anuales.

Sus ingresos medios anuales rondaban, por consiguiente, los 165.000 maravedís, una cifra modesta para un noble de la época. A pesar de ello, algunas mandas testamentarias revelan algunos rasgos propios de la mentalidad y de los usos caballerescos de la época, y denotan claramente el afán de imitar o remedar los usos funerarios de otros grandes caballeros, aunque mediase una enorme distancia económica con ellos. La sepultura, vistiendo el hábito de Santo Domingo, debía hacerse en la capilla de los Manuel que había fundado su padre en el convento de San Juan Pablo de Peñafiel, incluyendo además escudo de armas y una leyenda sobre su vida.

${ }^{85}$ Falleció en 1539. Su testamento en RAH, Salazar, M-1, fol. 251-254. 
Dejaba algunas sumas de dinero para la dotación de misas y sufragios en Toro y Peñafiel por él y por sus antepasados, limosnas para iglesias, ermitas, pobres y redención de cautivos, etc, siguiendo las normas usuales propias de las iglesias de la Trinidad y Santa Olalla de la ciudad de Toro. Entre los beneficiarios de su testamento también se encuentran un mayordomo, dos pajes, un escudero y nueve criados, además de un número indeterminado de hombres de a pie, acemileros y soldados que sirvieron en su capitanía, lo cual da idea del volúmen que llegó a tener el personal de su casa.

\section{RÉSUMÉ}

La điplomatie castellane à l'époque de Henry IV (1454-1474) a eté dirigée par un groupe réduit de conseillers royaux et des diplomates. Don Juan Manuel de Villena $(+1462)$ a eté un des plus important ambassadeurs à cette époque et il a eté chargé de negocier des affaires bilatérales entre la France et la Castille. Il appartenait à un des plus connus linages de la Castille mais sans Ie prestige et la richesse qu'il avait eu au XIVe siècle. Il a essayé de récupérer l'ancien pouvoir de sa famille en employamt ses relations dans le monde de la diplomatie. Il a obtenu une seigneurie dans les Asturies et une position économique de niveau moyen. Il a eu une spéciale relation avec le comte Jean $\mathrm{V}$ d'Armagnac, qui était a cette époque vassal du roi de Castille. Ses relations familières et politiques avec les conseillers royaux les plus célebres de son temps lui ont permis d'obtenir tous ces objetifs. Sa biographie nous aide à comprendre un peu mieux les usages diplomatiques de la monarchie castillane.

\section{SUMMARY}

The Castilian Diplomacy in the era of Henry IV (1454-1474) was driven by a small group of royal councellors and diplomats. Don Juan Manuel de Villena $(+1462)$ was one of the most important ambassadors on that time, and he was in charge of dealing with the bilateral affairs between Castile and France. He was part of a very known aristocratic family in Castile, altough with less prestige and wealth than that achieved in the fourteenth century. He tried to recover the previous influence of his family by using his contacts in the world of diplomacy. He managed to obtain a fiefdom in Asturias and a confortable economic position. He maintained a special relationship with the french count Jean V d'Armagnac, a vassal at that time of the king of Castile. He achieved all these goals helped by his family contacts and political relations with the most important royal councellors of his time. His biography helps us to understand several diplomatic customs of the castilian royal court.

\section{PROPAGANDA POLÍTICA Y PODER REAL \\ EN LA CASTILLA TRASTAMARA:}

UNA PERSPECTIVA DE ANÁLISIS

JosÉ MANUEL NIETO SORIA

Universidad Complutense de Madrid

SUMARIO

1. La "representación" del poder real. 2. La retórica política. 3. La 1. La representación de símbolos de la realeza. 5. La expresión artística y los escenarios de la monarquía. 6 . Los agentes de la propaganda regia.

\section{LA "REPRESENTACIÓN". DEL PODER REAL}

Se atribuye a Pascal una sentencia, según la cual, el fundamento más poder monárquico sería precisamente su representación ${ }^{2}$ sólido del poder moniderarse una interpretación un tanto exagerada de lo Seguramente puede considerarse una interpres de la Modernidad, fueron que, al menos a fines del Medievo y comienzos de la Montación del poder las monarquías, pero no cabe duda que esa representación del poder

1 Este trabajo se encuadra en el Proyecto de Investigación Multidisciplinar titulado Propaganda y legitimación en los origenes de la Monarquía Hispanica de Madrid.

visión multidisciplinar, financiado por la Universidad Complutense de Madrid.

${ }^{2}$ Peter LEWIS, Pourquoi aurait-on voulu réunir des états généraux, en France, a la fin du Moyen Âge, "Représentation, pouvoir et royauté à la fin du Moyen Age , ed. de Joe lo mismo que París, 1995, p. 123. En cierto modo, la opinión atribuída a Pascal vendría a decir lo nism en hacer Paris, 195 , p. Maquiavelo, según la cual, el hecho de gobernar consistiria ante todo en hacer creer.

"Antaio de Esudios Medievales", 25 (1995) 